\title{
La frustrada construcción de la "región" en el Ecuador (2007-2017): lecciones y perspectivas
}

\section{The failure of the construction of the region in Ecuador (2007-2017): lessons and perspectives}

\author{
Augusto Barrera Guarderas ${ }^{1}$ [D y Silvia Álvarez Villacrés² (1)
}

\begin{abstract}
RESUMEN
Este trabajo hace una revisión analítica del frustrado proceso de conformación de la región, establecida como nivel de gobierno intermedio en la Constitución Política del Ecuador de 2008. Más de una década después, la disposición constitucional quedó en letra muerta y por el contrario hay retrocesos en la calidad de la democracia territorial. Luego de precisar algunos conceptos y contextualizar el caso, el análisis se centra en dos ámbitos: por un lado, las limitaciones de los criterios sobre los cuales se construyó la noción de región; y por otro, los cambios de estrategia del gobierno nacional y otros actores relevantes que fueron diluyendo este precepto constitucional. Finalmente se formulan algunas consecuencias, conclusiones y perspectivas sobre las políticas de ordenamiento territorial en el país. El texto abona en la irresuelta problemática de las disparidades socioespaciales, las potencialidades y límites de la acción de los gobiernos nacionales sobre el territorio.
\end{abstract}

Palabras clave: Estado, región, descentralización, desconcentración, autonomía, nivel intermedio de gobierno, territorio.

\begin{abstract}
This paper makes an analytical review of the frustrated process of shaping the region, known as the intermediate level of government, established in the Political Constitution of Ecuador of 2008. After a decade of the constitutional provision, it remained a dead letter, and on the contrary, it could be argued that there are setbacks in the quality of territorial democracy. After specifying some concepts and contextualizing the case, the analysis focuses on two areas: on the one hand, the limitations of the criteria on which the notion of region was built; and on the other, the changes in the strategy of the national government that were dissolving this constitutional mandate. Finally, some consequences, conclusions and perspectives on land use planning policies in the country are tested. The text contributes to the unresolved problem of socio-spatial disparities, the potentialities and limits of the action of national governments on the territory.
\end{abstract}

Keywords: State, region, decentralization, desconcentration, autonomy, intermediate level of government, territory.

Director Oficina de transferencia de conocimiento e innovación social, Pontifica Universidad Católica del Ecuador PUCE. Profesor investigador invitado FLACSO sede Ecuador. Correo electrónico: abarrera@puce.edu.ec

Máster en Estudios Latinoamericanos. Investigadora y Especialista en Planificación, Descentralización y Ordenamiento Territorial. Correo electrónico: silvia_any@hotmail.com 


\section{El debate sobre la región en América Latina}

Desde el inicio de su proceso de conformación hasta la actualidad, los estados latinoamericanos no han alcanzado una razonable integración socioespacial. En el mismo país y a escasos kilómetros 'coexisten' sociedades con enormes brechas en su potencialidad productiva y en la calidad de vida de sus habitantes. El argumento genérico que explica el desarrollo desigual como resultado del capitalismo, no reduce la necesidad de comprender las específicas conformaciones de poder económico y político en clave especial, lo que algunos autores han denominado la cuestión regional (Coraggio et al., 1989).

A la impronta socioespacial que dejaron la conquista y la colonia en América Latina, le han seguido ciclos de auge/crisis de la economía dependientes de las demandas del mercado mundial y su correspondiente división de trabajo. En cada caso pueden identificarse factores como la valorización y sometimiento de la naturaleza convertida en recurso productivo, grandes desplazamientos demográficos, estrategias selectivas de intervención espacial del estado y reconfiguraciones territoriales de las relaciones de poder. Todo ello ha derivado en una geografía organizada en centros/periferias, regiones motrices/estancadas, territorios ganadores/perdedores (Santos \& Silveira, 2001; Boisier, 1992; 1994; 1996; 2006; Cuervo, 2006; Gómez, 2015; Silva, 2005; Bustos \& Prieto, 2019).

En este marco histórico-estructural, varios países han diseñado e implementado durante las últimas décadas políticas de ordenamiento territorial y de desarrollo regional. En algunos casos se buscaba atenuar o compensar las disparidades regionales; en otros, acelerar la inserción de ciertos territorios al mercado mundial. Varias experiencias contemplaban el reordenamiento de jurisdicciones territoriales basados en la creación, fusión, asociación o desagregación de unidades territoriales, así como estrategias de desarrollo y cohesión territorial en los que la construcción de un nivel intermedio entre el gobierno central y las localidades es un asunto medular (Buitelaar, 2015; Massiris, 2014).

La producción teórica y la experiencia práctica en la formulación de la política pública en este campo se interroga recurrentemente sobre ¿Cómo se conceptualiza el territorio y de manera particular las regiones? ¿Cómo se expresan estos conceptos en la política de ordenamiento territorial? ¿De dónde proviene el impulso regionalizador? ¿Qué dispositivos institucionales han sido utilizados? ¿Qué lecciones podemos sacar de estas experiencias?

Sobre estas preguntas, se desarrollan dos líneas de reflexión que sirven de marco analítico para el caso que se presenta: a) la definición del concepto de región, sus elementos constitutivos y el 'aterrizaje' de estas discusiones en el nivel político administrativo; b) el rol del Estado central y sus estrategias en el diseño de las políticas de ordenamiento territorial.

El concepto de región ha sido definido tradicionalmente en base a consideraciones topográficas, que enfatizan los sistemas geográficos y la continuidad territorial. Frente a esta visión se han desarrollado perspectivas relacionales que explican la región como un "cuadro compuesto por una serie de actores económicos e institucionales que interactúan a distintos niveles, con divergencias, trayectorias disímiles e interacciones cambiantes [...]; construcciones sociales que 
'aparecen' con un objetivo específico que la transforma en 'sujeto' a partir de 'relaciones de poder'" (Fernandez et al., 2012:30).

Esta especificidad de la región que la 'diferencia' de otras estructuras territoriales como un fenómeno político e ideológico es el producto de construcciones históricas viabilizadas por agentes políticos hegemónicos regionales en un espacio determinado (Saint-Geours, 1994, Quintero, 1991; Maiguashca, 1994). La región actúa como una comunidad imaginada que en virtud de su escala y fundamento territorial está más cercana a los intercambios sociales de base (Giménez, 1994). Bajo esta perspectiva, la identidad regional adquiere un valor sustancial, pues permite la construcción de una narrativa regional cohesionadora a partir de creencias, continuidad histórica, identidad activa, autorreferencia primaria, un espacio geográfico particular, en suma, sentido de pertenencia (Miller, 1997).

Este brevísimo recorrido de diversos abordajes conceptuales sobre la región podría sintetizarse, en la tesis de 'capas' (layers) conceptuales superpuestas que propone Boisier (2003): el subsistema subliminal (capitales intangibles), el axiológico (valores), el de acumulación (factores del crecimiento económico), el procedimental (la función gubernativa de administración), el decisional (los actores y la matriz de poder), el organizacional (organizaciones públicas y privadas), todos los cuales requieren articulaciones sinápticas densas y direccionadas mediante la introducción de sinergia cognitiva.

Otra discusión teórica y práctica se ha producido entre quienes argumentan que la economía -mundial y nacional- constituye, en última instancia a la región, frente a quienes comprenden las transformaciones territoriales con el concurso decisivo de la acción estatal. Desde la primera perspectiva, las transformaciones territoriales a nivel regional tienen como principal agente al mercado que busca la valorización como recurso productivo y su adecuada y funcional inserción al mercado mundial. (De Mattos, 2010; Boisier, 2006; Bustos \& Prieto, 2019). Pero las dinámicas de conformación regional comportan también la acción humana voluntaria y explícita, "en muchos casos el destino de ciertas modificaciones se mantiene porque existe [...] la más profunda convicción de su conveniencia y la más firme expectativa sobre el contenido de los resultados" (Cuervo, 2006). El estado tiene una función sustantiva en la configuración espacial a través de un amplio abanico de instrumentos de regulación y de intervención directa. Lipietz incorporó la dimensión espacial en el análisis de la intervención del estado, tanto en la (re) producción de la espacialidad de los modos de producción, lo cual remite a la noción de "administración del territorio" así como en la articulación espacial de los modos de producción. Esta doble dinámica se realiza a través de un conjunto de intervenciones que las denominada mediaciones (Lipietz, 1983). Los estados despliegan políticas espaciales de redistribución o equidad territorial para mitigar los efectos del desarrollo desigual, o en su defecto, renuncian a la regulación y liberan al mercado de las consecuencias espaciales de su desarrollo (Brenner et al., 2017).

Esta lógica se complejiza por la existencia de varios niveles gubernativos (nacional-intermedio-local) en la producción de estrategias de ordenamiento y desarrollo regional. En términos concretos han ocurrido muchas combinaciones posibles de producción de políticas de ordenamiento territorial y de manera particular de constitución de regiones. Las transformaciones territoriales de 'arriba hacia abajo' suceden a partir de un tipo de gestión con mayor protagonismo de los actores y niveles gubernamentales nacionales. Por el contrario, las experiencias de 'abajo 
hacia arriba' suelen responder a demandas desde los actores con pertenencia local y de entidades subnacionales (Arze et al., 2004). La tendencia desde arriba suele identificarse con la implementación de políticas regionales para enfrentar desequilibrios territoriales y desde abajo con iniciativas de políticas de desarrollo territorial como resultado de la concertación de diferentes actores. Idealmente estos puntos de vista son complementarios, aunque no siempre se da esta combinación necesaria (Alburquerque, 2013).

Sobre estas discusiones, se analiza la experiencia ecuatoriana que pretendió establecer un nivel intermedio de gobierno mediante la expedición de la Constitución de 2008.

\section{La reemergencia de la Región en la Constitución de Ecuador de 2008}

En el último medio siglo pueden identificarse tres momentos de desarrollo de las políticas de ordenamiento territorial en el Ecuador (Barrera, 2006; 2015). En el primero, entre los años sesenta y setenta, durante un corto y débil periodo de sustitución de importaciones, se impulsaron desde el gobierno central políticas de desarrollo regional. Primaba la idea del estado promotor para revertir el desarrollo desigual y las brechas territoriales. Durante este período el concepto de región como instancia de intervención fue recurrente en los planes de desarrollo ${ }^{3}$; sin embargo, en ninguno de estos casos se avizoró la posibilidad constituir a la región como un nivel de gobierno autónomo, sino como unidad de planificación e intervención desde la égida del estado central, en un típico modelo de planificación centralizada.

En el período siguiente, en la década de los noventa y la primera de este siglo, el concepto de región desapareció. En el marco de las políticas de privatización y desregulación en clave neoliberal, se produjo un giro hacia el paradigma de descentralización con un énfasis en el traslado de competencias desde el gobierno central hacia los gobiernos municipales bajo una modalidad dispersa y caótica de transferencia individual y voluntaria de cada competencia (Barrera \& Ramírez 1999; 2001). El final de ese ciclo mostró la regionalización del conflicto político como expresión de la crisis de hegemonía política y económica ${ }^{4}$ que vivió el país. Esto explica en gran medida la reconfiguración del sistema de representación política, que dio paso al triunfo de la denominada Revolución Ciudadana, que promovió la convocatoria a una Asamblea Nacional Constituyente y una nueva política de gestión del territorio.

El tercer momento ocurrió durante la década 2007-2017, en la que el gobierno intenta recuperar el rol del estado como agente principal y despliega un fuerte proceso de construcción de presencia estatal en el territorio. El punto clave fue el proceso constituyente que dio origen a la Constitución de 2008, en la que reemerge el concepto de región, como un nivel intermedio de gobierno orientado a consolidar una estructura nacional policéntrica (SENPLADES, 2007), en base a la definición, forma de gobierno y competencias que se muestran en la tabla siguiente: 
Cuadro $\mathrm{N}^{\circ} 1$.

La Región en el Ecuador a partir de la Constitución de 2008

\begin{tabular}{|c|c|c|}
\hline $\begin{array}{l}\text { Criterios para su } \\
\text { conformación }\end{array}$ & Forma de gobierno & Competencias \\
\hline $\begin{array}{l}\text {-Dos o más provincias } \\
\text { con continuidad terri- } \\
\text { torial, superficie mayor } \\
\text { a veinte mil kilómetros } \\
\text { cuadrados. } \\
\text {-Número de habitantes } \\
\text { que en conjunto sea su- } \\
\text { perior al } 5 \% \text { de la pobla- } \\
\text { ción nacional, formará } \\
\text { regiones autónomas de } \\
\text { acuerdo con la ley. } \\
\text {-La iniciativa para la con- } \\
\text { formación de una región } \\
\text { autónoma corresponde- } \\
\text { rá a los gobiernos pro- } \\
\text { vinciales o distritos me- } \\
\text { tropolitanos. }\end{array}$ & $\begin{array}{l}\text {-Cada región autónoma elegi- } \\
\text { rá por votación a su consejo } \\
\text { regional y a su gobernadora o } \\
\text { gobernador regional. } \\
\text {-Los consejeros regionales se } \\
\text { elegirán de forma proporcio- } \\
\text { nal a la población urbana y } \\
\text { rural. } \\
\text {-Cada gobierno regional es- } \\
\text { tablecerá en su estatuto los } \\
\text { mecanismos de participación } \\
\text { ciudadana que la Constitu- } \\
\text { ción prevea. } \\
\text {-Cada distrito metropolitano } \\
\text { autónomo tendrá un concejo } \\
\text { elegido por votación popular. } \\
\text {-La alcaldesa o alcalde me- } \\
\text { tropolitano será su máxima } \\
\text { autoridad administrativa y } \\
\text { presidirá el concejo con voto } \\
\text { dirimente. }\end{array}$ & $\begin{array}{l}\text {-Planificar el desarrollo regional y } \\
\text { formular los correspondientes pla- } \\
\text { nes de ordenamiento territorial. } \\
\text {-Gestionar el ordenamiento de cuen- } \\
\text { cas hidrográficas y propiciar la crea- } \\
\text { ción de consejos de cuenca. } \\
\text {-Planificar, regular y controlar el } \\
\text { tránsito y el transporte regional y el } \\
\text { cantonal en tanto no lo asuman las } \\
\text { municipalidades. } \\
\text {-Planificar, construir y mantener el } \\
\text { sistema vial de ámbito regional. } \\
\text {-Otorgar personalidad jurídica, re- } \\
\text { gistrar y controlar las organizaciones } \\
\text { sociales de carácter regional. } \\
\text {-Determinar las políticas de investi- } \\
\text { gación e innovación del conocimien- } \\
\text { to, desarrollo y transferencia de tec- } \\
\text { nologías. } \\
\text {-Fomentar las actividades producti- } \\
\text { vas regionales. } \\
\text {-Fomentar la seguridad alimentaria } \\
\text { regional. } \\
\text {-Gestionar la cooperación interna- } \\
\text { cional para el cumplimiento de sus } \\
\text { competencias. }\end{array}$ \\
\hline
\end{tabular}

Fuente: elaboración propia basada en Constitución Política (2008) y COOTAD (2010).

La Constitución y luego el Código Orgánico de Organización Territorial Autonomía y Descentralización (COOTAD) fijaron el plazo para la conformación de regiones autónomas que en ningún caso debía exceder los ocho años. Esta forma transicional pero dirigida que estableció la Carta Suprema, partía del supuesto que era imposible imponer un mapa político administrativo del país desde arriba y por ello se apostaba a una transición voluntaria.

\section{Los criterios constitutivos de la Región}

Si bien se optó por una estrategia de transición "voluntaria" (Muñoz et al., 2008), los requisitos dispuestos en la Constitución (Art.244 y 245) y el COOTAD (Art. 15) para la conformación de regiones llevaban a una específica forma de regionalización que permita el cumplimento de varios objetivos. Entre los más relevantes: la integración de zonas más amplias que las provincias para facilitar la planificación y la gestión pública; el impulso de territorios equilibrados (equipotentes), 
es decir relativamente equivalentes en pesos poblacionales, infraestructura, aparato productivo y económico; la 'generación' de una articulación espacial horizontal bajo el eje amazonia-sierra-costa que potencie las complementariedades productivas y logísticas y revierta el determinismo geográfico de las regiones naturales clásicas. Así configurada la región cumpliría un rol de bisagra entre el nivel nacional y los niveles locales (SENPLADES, 2009).

El cuadro siguiente presenta esos criterios, su definición y variables. Identifica ventajas comparativas y competitivas para el desarrollo de cada región; las condiciones que pudieran entorpecer el desarrollo de actividades productivas y las amenazas naturales y antrópicas ligadas a la vulnerabilidad y riesgos de las posibles regiones y sectores, así como el equilibrio territorial sobre aspectos de vialidad e infraestructura básica (SENPLADES, 2007).

Cuadro $\mathrm{N}^{\circ} 2$.

Criterios para la conformación de regiones de planificación

\begin{tabular}{|c|c|c|}
\hline Criterios & Definición & Variables \\
\hline 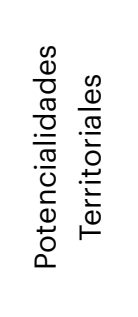 & $\begin{array}{l}\text { Son elementos o componentes del terri- } \\
\text { torio que presentan ventajas comparati- } \\
\text { vas y competitivas para el desarrollo de } \\
\text { una región: agrícola, ganadero, forestal, } \\
\text { turístico, étnico, energético, ambiental, } \\
\text { infraestructura, entre otros. }\end{array}$ & $\begin{array}{l}\text { Grupos étnicos, recursos turísticos, ar- } \\
\text { tesanías; recursos hídricos, mineros; } \\
\text { petroleros; agropecuarios; energéticos. } \\
\text { Sistema nacional de áreas protegidas; } \\
\text { Estructura vial; Puertos marítimos; Aero- } \\
\text { puertos principales; Sectores producti- } \\
\text { vos. }\end{array}$ \\
\hline 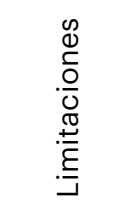 & $\begin{array}{l}\text { Son condiciones físicas y meteorológicas } \\
\text { propias del capital natural, que de alguna } \\
\text { forma inciden en el desarrollo de activi- } \\
\text { dades agro-productivas. }\end{array}$ & Topográficas; Climáticas; Edáficas. \\
\hline $\begin{array}{l}\frac{\infty}{\sigma} \\
\frac{\varepsilon}{0} \\
\frac{0}{0} \\
\frac{0}{2}\end{array}$ & $\begin{array}{l}\text { Tanto las amenazas naturales como las } \\
\text { socio-naturales y antrópicas, ligadas con } \\
\text { la vulnerabilidad y riesgos de los diversos } \\
\text { sectores interfiriendo, restringiendo o li- } \\
\text { mitando la capacidad de uso de los sue- } \\
\text { los. }\end{array}$ & $\begin{array}{l}\text { Inundaciones; Desertización; Volcáni- } \\
\text { cos; Sísmicos; Movimientos de masa; } \\
\text { Conflictos de uso del suelo; Seguridad. }\end{array}$ \\
\hline 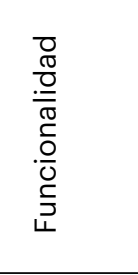 & $\begin{array}{l}\text { Análisis de funcionalidad entre regiones, } \\
\text { su importancia en términos de planifica- } \\
\text { ción y desarrollo, ligada al papel clave } \\
\text { que tiene la integración territorial. }\end{array}$ & $\begin{array}{l}\text { Infraestructura para el desarrollo. } \\
\text { Flujos ligados a actividades económi- } \\
\text { cas de la población (comercio, turismo, } \\
\text { mercados de trabajo, entre otros. } \\
\text { Movimientos poblacionales (migración } \\
\text { interna / externa). }\end{array}$ \\
\hline 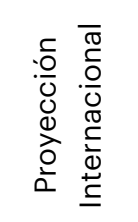 & $\begin{array}{l}\text { El papel de la región en la integración a } \\
\text { nivel continental y mundial en el marco } \\
\text { de la globalización de los flujos (personas } \\
\text { e información) y de la economía. }\end{array}$ & $\begin{array}{l}\text { Exportaciones e importaciones. } \\
\text { Destinos y fuentes del comercio exte- } \\
\text { rior. } \\
\text { Telecomunicaciones. } \\
\text { Zonas de conservación. }\end{array}$ \\
\hline
\end{tabular}


Estos criterios se expresaron finalmente en los escenarios de zonificación del ejecutivo que debía servir de 'modelo' para la regionalización (SENPLADES, 2007). Se trataba de construir un 'mapa de llegada' que ordene todas las iniciativas de ordenamiento territorial en la figura que se presenta a continuación.

Figura $\mathrm{N}^{\circ} 1$.

Regiones Administrativas de Planificación (2007), Valor Agregado Bruto (VAB) y Población (2017)

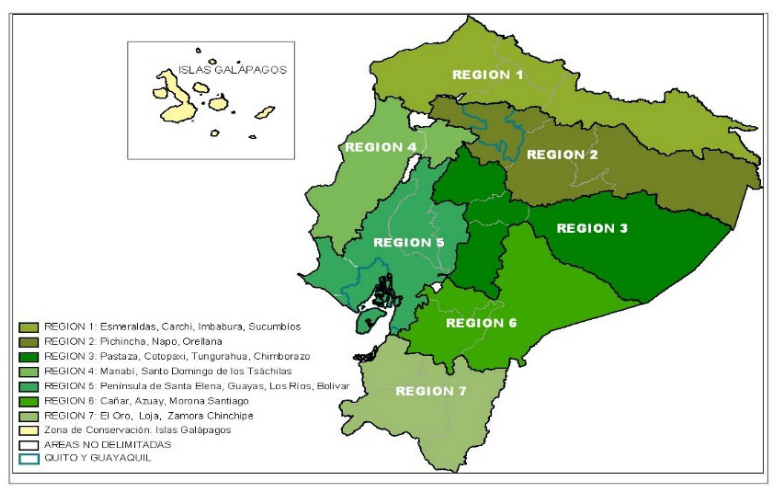

\begin{tabular}{|c|c|c|}
\hline Zona & VAB 2017 & Población 2017 \\
\hline zona 1 & 7065113,02 & 1423565 \\
\hline zona 2 & 6395257,09 & 696817 \\
\hline zona 3 & 7229897,23 & 1657529 \\
\hline zona 4 & 8098577,89 & 2009040 \\
\hline zona 5 & 8843282,14 & 2678261 \\
\hline zona 6 & 6643479,69 & 1290230 \\
\hline zona 7 & 5496408,46 & 1308630 \\
\hline zona 8 & 22884119,6 & 3029330 \\
\hline zona 9 & 24426597,9 & 2644145 \\
\hline
\end{tabular}

Fuente: elaboración propia basada en Banco Central del Ecuador (BCE), 2017 y SENPLADES, 2007.

El resultado esperado era la constitución de 7 regiones, a las que debería añadirse 2 distritos metropolitanos que podían adoptar un camino similar. Este mapa de 9 gobiernos autónomos regionales reducía -por agregación- las disparidades demográficas y económicas mucho más evidentes si las unidades de análisis son las 24 provincias y los 221 cantones (Barrera et al., 1999); equilibra el peso demográfico y por ende político, así como la concentración de recursos productivos, públicos y privados. La agregación en regiones permitiría revertir la espiral de concentración económica, financiera, demográfica y política.

Lamentablemente nada de esto sucedió. Mientras el ejecutivo sí desconcentró sus servicios y fortaleció su presencia territorial, ninguna provincia dio pasos en dirección a convertirse, junto con sus vecinas, en regiones.

\section{Una aproximación crítica a la concepción de región}

Los criterios establecidos para la regionalización en el caso ecuatoriano enfatizan los aspectos topográficos y económicos por sobre los ámbitos de la gobernabilidad e identidad territorial. En este acápite se muestran diferentes reflexiones sobre los criterios de región elaboradas para los casos argentino y chileno durante las últimas décadas. Más que un análisis de los contextos políticos e institucionales, se quiere mostrar los distintos abordajes de la categoría región en la formulación de políticas públicas.

Arenas et al (2007) realiza un análisis crítico sobre la clasificación de los razonamientos usados en las políticas de descentralización en Chile a finales de los setenta en las que se adoptan seis 
categorías o "criterios de base o de primer orden": medio natural, demográfico territorial, realidad sociocultural, medio productivo, administrativo y servicios públicos y criterio político electoral (2007). A partir de la identificación de los límites de este abordaje, Rehren y otros autores plantean la necesidad de establecer nuevos elementos que aporten a un proceso de construcción de regiones, considerando los posibles impactos en términos del equilibrio socio territorial y una visión más intersectorial y prospectiva del territorio que se quiere establecer como región (Reheren et al., 2018).

Proponen así lo que denominan criterios de segundo orden: sostenibilidad territorial, gobernabilidad territorial, capital endógeno, recursos de conectividad e historicismo territorial; y los formulan como características que actúan como filtros no solo técnicos sino también políticos para recoger la complejidad y el dinamismo del proceso regional y darle viabilidad, consistencia y pertinencia (Reheren et al., 2018).

Unas décadas antes, para el caso argentino, Rofman $(1974 ; 1979 ; 1997)$ incorporaba un abanico de categorías de caracterización regional como las desigualdades, los circuitos productivos 'regionales' y la pobreza. El refinamiento de estos trabajos se sintetizó en criterios metodológicos para la diferenciación y clasificación de las regiones, entre los cuales pueden señalarse la capacidad productiva, los índices de productividad, el nivel de adopción del cambio tecnológico, el nivel de difusión del sistema capitalista, la cualificación de la fuerza de trabajo, la diversificación y especialización económicas, los niveles salariales, la dotación de infraestructura, el régimen de tenencia de la tierra, la capacidad de generación y retención de excedentes, la flexibilidad de los procesos de producción, la importancia de la industria y del sector agrario, la estructura del aparato estatal, los niveles de urbanización y el papel de las clases dominantes (Rofman, 1979). Aunque algunas críticas señalan este enfoque por su débil comprensión del territorio y el abordaje de fenómenos económico-sociales como realidades desarrolladas sobre el espacio (Gómez, 2015), no deja de ser una perspectiva relevante.

El cuadro 3 muestra los tres conjuntos de criterios a los que se ha hecho referencia. Aunque la matriz analítica no es plenamente correspondiente, pues se trata de marcos y desarrollos metodológicos diversos, permite abrir algunas reflexiones en torno al hilo argumental de este trabajo.

Si bien el ejercicio recoge contextos y enfoques distintos, muestra los aspectos sustantivos sobre cómo se conceptualiza la región para fines de política pública. En el caso ecuatoriano se atiende especialmente las variables biofísicas, entiende la potencialidad como un inventario de recursos y enfatiza la conectividad con el entorno, antes que como red que cohesione las dinámicas endógenas.

Las dimensiones económico-productivas se tratan en la aproximación de Rofman (1979) desde categorías más complejas como el nivel de desarrollo del capitalismo, los regímenes de propiedad o los mecanismos de producción de desigualdades espaciales. La formulación realizada por SENPLADES (2007) se concentra en factores de potencialidad productiva enfatizando los aspectos materiales de la región expresados en la densidad de recursos e infraestructura de manera más descriptiva que sistémica, no alcanzan a ser pensados como criterios de sostenibilidad territorial a partir de la caracterización de las dinámicas de producción y reproducción de esas desigualdades, vale decir del tipo de inserción de la región en la dinámica de reproducción capitalista. 
Cuadro $\mathrm{N}^{\circ} 3$.

Relación criterios de segundo orden con el caso ecuatoriano

\begin{tabular}{|c|c|c|}
\hline $\begin{array}{c}\text { Criterios "segundo orden" } \\
\text { Reheren }\end{array}$ & $\begin{array}{c}\text { Criterios regiones } \\
\text { Rofman }\end{array}$ & $\begin{array}{l}\text { Criterios región } \\
\text { caso ecuatoriano }\end{array}$ \\
\hline $\begin{array}{l}\text { Historicidad territorial } \\
\text { Factores identitarios y funcio- } \\
\text { nales de orden histórico y cul- } \\
\text { tural, frontera subjetiva para } \\
\text { reconocerse como integrante } \\
\text { de un territorio. } \\
\text { Sostenibilidad territorial } \\
\text { Base territorial suficiente en } \\
\text { términos de uso y explotación } \\
\text { para potenciar el desarrollo } \\
\text { regional en áreas productivas } \\
\text { y generación de empleo (dota- } \\
\text { ción y flujos de materias e in- } \\
\text { sumos). } \\
\text { Gobernabilidad territorial } \\
\text { Garantizar que la región sos- } \\
\text { tenga autonomía territorial, } \\
\text { configurando un tejido social y } \\
\text { una institucionalidad. } \\
\text { Capital endógeno } \\
\text { Dotación institucional y profe- } \\
\text { sional en el ámbito de lo públi- } \\
\text { co, privado y académico. } \\
\text { Recursos de conectividad } \\
\text { Infraestructura, transporte y } \\
\text { comunicación, equipamiento } \\
\text { público de servicios }\end{array}$ & $\begin{array}{l}\text { Capacidad productiva } \\
\text { Índices de productividad, } \\
\text { adopción cambio tecnológico, } \\
\text { nivel de difusión del sistema } \\
\text { capitalista; diversificación y } \\
\text { especialización económicas. } \\
\text { Nivel de desarrollo/ difusión } \\
\text { del capitalismo } \\
\text { Estructura del aparato estatal, } \\
\text { Especialización económica, } \\
\text { desarrollo industrial, Régimen } \\
\text { de tenencia de la tierra. } \\
\text { Factores de desarrollo Estruc- } \\
\text { tura del aparato estatal, niveles } \\
\text { de urbanización, papel de las } \\
\text { clases dominantes, cualifica- } \\
\text { ción de la fuerza de trabajo. } \\
\text { Dotación de infraestructura, } \\
\text { la capacidad de generación } \\
\text { y retención de excedentes, la } \\
\text { flexibilidad de los procesos de } \\
\text { producción. }\end{array}$ & $\begin{array}{l}\text { Potencialidades territoriales } \\
\text { Grupos étnicos. } \\
\text { Movimientos poblacionales } \\
\text { (migración interna / externa). } \\
\text { Recursos turísticos/ artesa- } \\
\text { nías, hídricos; mineros; petro- } \\
\text { leros; agropecuarios; energé- } \\
\text { ticos; } \\
\text { Sistema nacional de áreas pro- } \\
\text { tegidas. } \\
\text { Funcionalidad y Proyección } \\
\text { internacional } \\
\text { Infraestructura para el desa- } \\
\text { rrollo. } \\
\text { Flujos ligados a actividades } \\
\text { económicas de la población: } \\
\text { comercio, turismo, mercados } \\
\text { de trabajo, entre otros, secto- } \\
\text { res productivos. } \\
\text { Estructura vial, puertos, aero- } \\
\text { puertos principales. }\end{array}$ \\
\hline
\end{tabular}

Fuente: Adaptado de Rehren, Arenas, \& Hidalgo (2018) / SENPLADES (2007)/ Rofman (1979).

Los criterios vinculados a la historicidad y gobernabilidad están absolutamente ausentes en el caso ecuatoriano, pese a la enorme heterogeneidad de las potenciales regiones. Los elementos de orden sociocultural que hacen que la región sea un sujeto, así como las específicas formas de poder social que se expresan son pasados por alto. La propuesta de criterios del caso ecuatoriano apunta al principio de equilibrio regional centrado en potencialidades biofísicas con un débil anclaje a factores identitarios y funcionales de orden histórico y cultural. Desde el enfoque de desarrollo coloca el énfasis en la reorganización institucional para mejorar la cobertura, más que en las articulaciones y relaciones territoriales necesarias para vincular nodos de productividad sistémica. 


\section{Las metamorfosis de la estrategia: la región sin sujetos}

A las limitaciones en la definición de los criterios de regionalización se añadió otro factor tanto o más negativo: la estrategia de regionalización se quedó sin actores que la impulsen. Durante la fase inicial de diseño del proceso se suponía que ocurriría la convergencia de estrategias provenientes de múltiples actores; de manera particular de las demandas autonomistas (desde abajo), con la convicción y acción del gobierno central de acortar las brechas con un claro enfoque territorial. Esos supuestos no ocurrieron. Por un lado, se observó una progresiva disminución de los impulsos regionalistas y autonomistas de varios de los actores locales hasta su virtual anulación. Al punto tal que el Consorcio de gobiernos provinciales ${ }^{5}$ solicitó la supresión de la norma que establecía fecha a la transición, con lo que quedó asegurado que el camino hacia la regionalización no ocurrirá nunca. Pesó más la estructura político-burocrática local-provincial existente y sus soportes económicos y políticos.

Pero también el gobierno central modificó su horizonte de regionalización. La estrategia para la conformación de las regiones fue pensada en tres fases. En la primera se trataba de construir las regiones de planificación, materializada en el proceso de desconcentración administrativa del Ejecutivo y la reorganización (desaparición) de las entidades de desarrollo para efectos de promover un nivel regional de planificación territorial. Un segundo momento debía esperar la formación de regiones como división política-administrativa, es decir la transición entre regiones de planificación y regiones como división política administrativa catalizada a través de incentivos fiscales, fomentar las actividades empresariales y microempresariales, orientar su localización y repartir equilibradamente las actividades económicas reforzando el potencial de desarrollo endógeno. Como continuidad de este proceso, se llegaría a las regiones autonómicas, es decir la constitución del nivel intermedio de gobierno con ampliación de competencias, funciones y responsabilidades a través del estatuto autonómico que le otorgaría potestad legislativa. (SENPLADES, 2007)

El ideal desarrollo de estas fases suponía la formulación de planes de ordenamiento territorial para cada región, impulsados desde el gobierno central. De esta manera, se esperaba que después de algunos años de poner en práctica la planificación regional se validara su funcionamiento para derivar en la constitución efectiva de regiones como parte de la reorganización territorial y de una nueva división político-administrativa (SENPLADES, 2007). Sin embargo, esta proyección apenas llegó a la primera fase y en el trayecto de diez años sufrió importantes transformaciones vinculadas a los cambios en los planes nacionales.

\section{Modificaciones en el enfoque regional de los planes nacionales}

En el periodo analizado discurrieron tres planes nacionales de desarrollo que expresaban el enfoque estratégico del gobierno nacional; de hecho, se trata de tres periodos consecutivos de planificación regidos por el mismo presidente, cuya gestión valoraba el plan como guía de acción.

El cuadro siguiente muestra los tres planes analizados bajo la variable de la evolución del modelo de desarrollo, el concepto de región, los énfasis en las estrategias territoriales y el rol que se

Organismo que agrupa a todos los Consejos Provinciales del país. 
le asigna a la región. En cada uno de estos tres momentos se precisan los hitos que van evidenciando los cambios a lo largo de proceso.

Cuadro $\mathrm{N}^{\circ} 4$.

Elementos territoriales en los Planes Nacionales

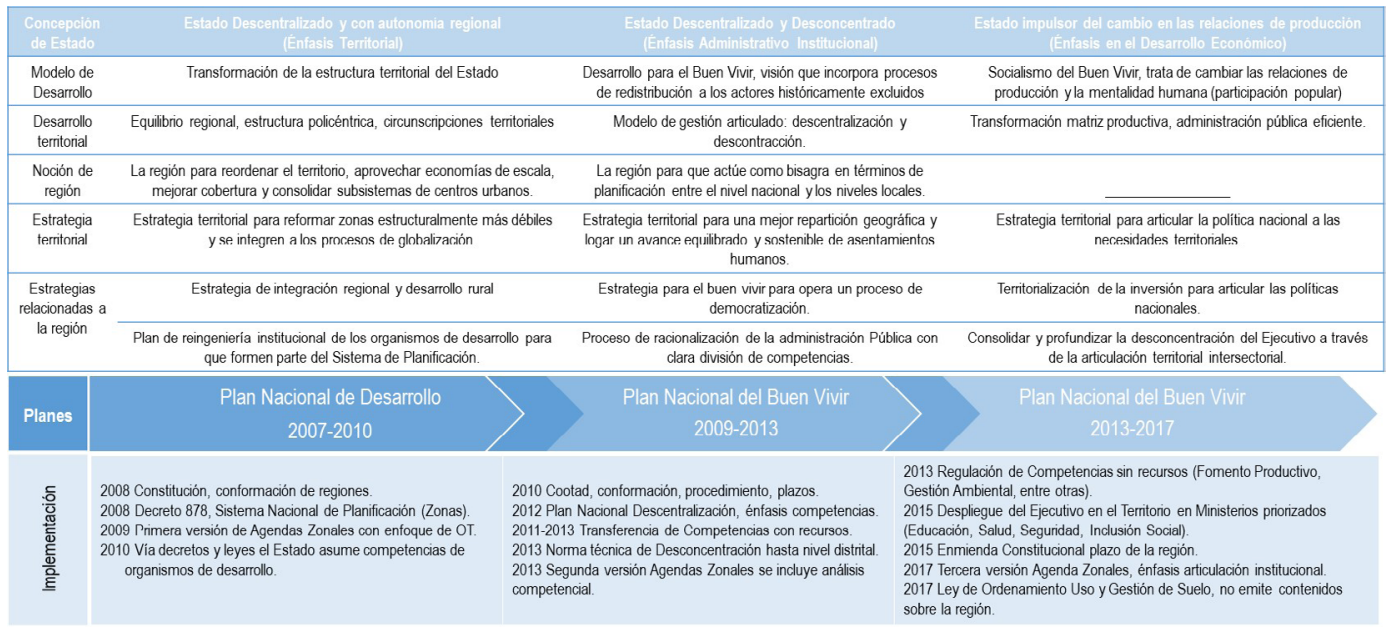

Fuente: elaboración propia basada en SENPLADES 2007, 2009, 2013.

Los tres planes nacionales corresponden a la evolución del pensamiento del gobierno durante el período 2007-2017. En cada uno de ellos se establecen dispositivos institucionales, normativos y metodológicos para la implementación de políticas y estrategias territoriales, tal como se muestra a continuación en el análisis de cada uno de ellos.

\section{1) 2007 -2009 - Énfasis Territorial}

En este primer momento, la idea de una profunda reforma del Estado tiene como correlato una transformación significativa del territorio. Se apuesta por un Estado descentralizado y con autonomía regional anclado a un modelo de desarrollo endógeno. El desarrollo territorial es visto a partir del equilibrio regional, con la idea de repartir el crecimiento entre localidades y entre áreas urbanas y rurales. La Estrategia Territorial Nacional (ETN) tiene la finalidad de reforzar zonas estructuralmente más débiles e impulsar mejores condiciones de vida y de trabajo; mientras que los centros urbanos deben integrase a los procesos de globalización. La descentralización y desconcentración son parte de la reorganización administrativa para consolidar una estructura policéntrica en la que la autonomía es un elemento fundamental para definir nuevas relaciones y articulaciones entre los diferentes niveles de gobierno (SENPLADES, 2007). Se afirma que el nivel central fortalecerá a los niveles intermedios para convertirlos en actores capaces de generar desarrollo endógeno en sus territorios (Carrión et al., 2019).

A partir de estas líneas programáticas se desarrollaron dispositivos normativos como el establecimiento del Sistema Nacional de Planificación en el que se definen las (regiones) zonas administrativas de planificación (2008), con lo que se hace efectiva la primera fase de la propuesta regional y se inicia la implementación de la estructura institucional del gobierno central en la 
escala regional. El gobierno central desconstituye los 13 Organismos de Desarrollo que actuaban a nivel territorial. En este momento, "el territorio adquiere un rol subsidiario, como un contenedor, un receptor, un reflejo y un discurso- de los objetivos y las políticas del desarrollo nacional." (Carrión et al., 2019:40). Tal como se planeaba en la fase inicial de la estrategia de implementación, se formularon las primeras agendas zonales (2009-2013) como planes de ordenamiento territorial regional, con el afán de estimular a los gobiernos provinciales en la conformación de regiones de acuerdo con el cálculo realizado por el Ejecutivo.

\section{2) 2009-2013 - Énfasis administrativo institucional}

En el segundo momento, la apuesta regional tiene una importante variación con la propuesta inicial. El foco en este momento ya no se ubica en el desarrollo equilibrado del territorio sino más bien en la dimensión administrativa institucional. El énfasis está en el Estado central, la región es entendida bajo la lupa competencial y el proceso de desconcentración opera con mayor fuerza. El marco programático de este momento es del desarrollo para el Buen Vivir desde donde lo territorial está ligado a la consolidación de un modelo de gestión estatal articulado a través de los procesos de descentralización y desconcentración. La concepción de la región tiene un marcado énfasis en la racionalización de la administración pública con división de competencias. El nivel regional mantiene su función como bisagra entre el nivel nacional y los niveles locales. En este momento aparece, como parte de las líneas estratégicas, la elaboración de agendas zonales y varios instrumentos de coordinación del nivel central para potencializar acuerdos básicos para el desarrollo y el ordenamiento territorial (SENPLADES, 2009).

La materialización de este momento se da con la expedición del COOTAD (2010) en el que se define a la descentralización como la transferencia de competencias desde el gobierno central hacia los subnacionales y contempla la conformación regional como agregado y no como parte constitutiva del proceso. Se emite el Plan Nacional de Descentralización cuyo contenido programático y operativo escasea de estrategias para impulsar una agenda de regionalización. Mientras que, desde la desconcentración, se dispone la presencia institucional en gran parte del espacio nacional bajo la tutela del gobierno central, en servicios universales como la salud, educación, seguridad e inclusión social a través de las nociones espaciales de circuitos y distritos administrativos (2013). En esta fase se deja de lado el sujeto regional para enfatizar en la organización administrativa y la modernización institucional.

\section{3) 2013-2017- Énfasis Cambio de Matriz Productiva}

En este último Plan, denominado "Socialismo del Buen Vivir" el énfasis está en el desarrollo económico dirigido por el gobierno central. Las estrategias, políticas y proyectos emblemáticos vinculados al cambio de matriz productiva carecen de conexión territorial dejando de lado la integración regional y la economía de escalas.

El Plan incorpora un acápite denominado Estrategia Territorial Nacional (ETN) que se propone de un lado, lograr la articulación programática en el territorio a través de varios mecanismos convergentes: agendas zonales, presupuestos territorializados, identificación de brechas sociales, etc.; y por otro, la integralidad de la visión del gobierno en el territorio, en varios ámbitos que incluyen las implicaciones espaciales del cambio de la matriz productiva, los instrumentos de 
inversión pública, o la localización de los servicios públicos. El impulso de este proceso viene fuertemente desde el Estado central (Barrera, 2014).

En este momento, a nivel programático se abandona el proceso de regionalización y se emiten lineamientos a nivel operativo para fortalecer otro tipo de articulaciones como la conformación de mancomunidades para favorecer procesos de integración (SENPLADES, 2013).

Como parte del paquete de enmiendas constitucionales propuestas en 2015, se amplía el plazo de conformación regional (a tiempo indefinido), con ello se renuncia en los hechos a la idea de un proceso de transición para conformar regiones. En el plano operativo, las agendas zonales pierden peso en su articulación con otros niveles de gobierno y se convierten en instrumentos de coordinación de la acción del ejecutivo.

A esta altura, el despliegue institucional del gobierno central en el territorio nacional encontraba a 67 instituciones del Ejecutivo desplegadas a través de 290 coordinaciones zonales, 76 direcciones provinciales, 406 entidades operativas y 387 oficinas técnicas. Un total de 1159 entidades con infraestructura física, talento humano, equipamiento y presupuestos era el interlocutor frente a las 24 prefecturas debilitadas política y financieramente y a las 221 heterogéneas municipalidades. Se marcaba así el predominio absoluto del proceso de desconcentración frente a una pretendida regionalización (Álvarez, 2017).

Estos tres momentos delinearon una estrategia operada desde el gobierno central, vaciada de una base material histórica, económica, cultural, política y social que terminó por disolver los sujetos regionales. No contó con la demanda ni la simpatía social por lo que terminó siendo un proceso implementado por el propio aparato burocrático que expandió la presencia del Estado central en los territorios (Carrión et al., 2019).

\section{Conclusiones y perspectivas}

1. En los años siguientes a la Constitución de 2008 se esperaba la conformación de las regiones. De hecho, hasta el año 2016, debió ocurrir la transición hacia el gobierno intermedio (7 regiones más 2 distritos metropolitanos). Hasta la actualidad no existen procesos de unificación de provincias en regiones, tan solo un proceso tentativo de constitución de gobierno autónomo regional con alguna vitalidad y es precisamente el del centro: Quito Distrito Metropolitano. De ahí que la apuesta por construir un nivel de gobierno regional establecido por la Constitución Política de Ecuador quedó trunca.

2. Los conceptos y criterios de región formulados desde el gobierno central enfatizaron variables biofísicas, densidades poblacionales institucionales y fiscales y un inventario de recursos localizados en el territorio. No se valoró la historicidad territorial, la gobernanza ni el potencial desarrollo endógeno. El desprecio a estas dimensiones colocó el proceso en el terreno del diseño administrativo y no en el del desarrollo regional, como recomiendan los debates y la experiencia de política pública en América Latina. 
3. Pese a que el punto de llegada era un "mapa" con regiones equipotentes, es decir territorios con parecidas capacidades demográficas, políticas y económicas, no se logró construir una propuesta conceptual ni metodológica que comprenda realmente la dinámica del proceso espacial y por lo tanto estableciera contenidos integradores y dinámicos (prospectivos) para la construcción regional; se trató de un análisis plano y lineal.

4. La estrategia que se adoptó apuntaba a que el tejido territorial diseñado por el Ejecutivo decante en regiones, de modo que se transite desde una región plan a una plenamente autónoma. Sin embrago, al reabsorberse las demandas autonomistas y regionales, el propio ejecutivo fue trastocando su concepto y estrategia inicial. Los actores locales reacomodaron sus demandas en el orden estatal establecido y desistieron o mutaron sus demandas de constitución regional. El asedio autonomista en la Constitución de 2008 reflejaba más bien una disputa del tipo de Estado desde una perspectiva neoliberal, antes que su efectiva democratización territorial.

5. A la par que los actores locales abandonaron la estrategia de conformación regional, el ejecutivo profundizó un intenso proceso de desconcentración bajo el cual se reorganizó la distribución de entidades y de prestadores de servicios a nivel de zona, distrito y circuito, de manera mucho más intensa que en cualquier otro periodo histórico. El territorio terminó adquiriendo un rol de receptor bajo el predomino absoluto del gobierno central. En este momento, la malla institucional-territorial del ejecutivo no coincide con la de los gobiernos autónomos, complejizando fuertemente los mecanismos de concurrencia y coordinación de planes, proyectos y presupuestos.

6. La estructura constitucional prefiguraba con toda claridad la formación de un nivel intermedio muy robusto; las actuales provincias tienen una débil definición de competencias, carecen de recursos propios y, lo que es más grave, adolecen de una contradicción entre su origen electoral (toda la votación de su jurisdicción) y su obligación constitucional (atender a la población rural). La parálisis del nuevo nivel intermedio debilita la democracia territorial.

7. La trasformación en los planes nacionales de desarrollo muestra también la metamorfosis del concepto de región y la concepción del desarrollo económico. El primer plan define mejor una estrategia con el territorio -entiéndase la ecuación sociedad- economía-espacio. En el segundo plan este elemento se difumina y hay una marcada centralidad del estado y la determinación de competencias. En el tercer plan se ven los territorios como los escenarios del cambio de matriz productiva entendida como un ejercicio de arriba hacia abajo. Se procesa así una paulatina desconexión de la propuesta regional con el modelo de desarroIlo o la estrategia productiva. El foco en lo productivo se concentra más sobre los impactos de la estrategia que en la producción de mecanismos de desarrollo de las regiones.

8. Fue decantando una racionalidad espacial que reproduce la diferenciación de funciones y responsabilidades. Mientras las instituciones territoriales desconcentradas son responsables de las acciones relativas a coordinación, gestión y evaluación, las decisiones mayores de rectoría, control y regulación se mantienen en manos de las autoridades nacionales. Esta racionalidad es contraria a la democratización territorial en la medida en que se re- 
centraliza y reconcentra el poder decisional: las funciones "inteligentes" se mantienen en el centro, mientras se desconcentran aquellas más "operativas"

9. La estructura de la Constitución de 2008 establecía algunas competencias exclusivas para los gobiernos regionales. De manera muy importante las relativas a la gestión de las cuencas hidrográficas, el fomento del desarrollo productivo local y las relativas a políticas de innovación y conocimiento. Estas tres competencias clave para cualquiera forma de desarrollo sostenible de este siglo siguen en una difusa situación: mal asumidas por el gobierno nacional y pésimamente gestionadas desde una perspectiva espacial. Es sin duda uno de los grandes pasivos del proceso.

10. La experiencia ecuatoriana, como en su momento la chilena o argentina abren grandes interrogantes sobre a eficacia a largo plazo de la política de desarrollo regional y de manera particular el ordenamiento territorial y las formas de gobernanza. Si bien podría decirse que las políticas de arriba hacia abajo terminan esterilizando la formación de actores locales, no es menos cierto que sin esa concurrencia regional-nacional es muy difícil lograr resultados. La discusión sobre los criterios, las formas, las temporalidades, las políticas de incentivos y probablemente una lógica de geometría variable podrían dar pistas para una nueva generación de política de ordenamiento territorial. Queda claro que no puede ser un ejercicio de planificación sin sujetos, y que solo la concurrencia persistente de varios niveles de actores y de gobierno puede acercarnos a una mayor justicia territorial.

\section{Bibliografía}

ALBURQUERQUE, F. Política Regional y Desarrollo Territorial en América Latina y el Caribe. Washington DC: FOMIN/BID, 2013.

ÁLVAREZ, S. Gubernamentalidad y Administración Territorial: La Descentralización en el Ecuador 2006-2016. Quito: UASB, 2017.

ARENAS, F. \& HIDALGO, R. ORELLANA, A. \& GASTÓN, A. Propuesta de nuevos criterios para redefinir unidades político administrativas regionales en Chile. Santiago de Chile: Ediciones UC, 2007.

ARZE, J. \& MARTíNEZ, J. Descentralización en América Latina desde una perspectiva de países pequeños. México D.F.: Centro de Investigación y Docencia Económicas, 2004. Vol. XIII.

BARRERA, A. El proceso de descentralización en Ecuador, 8 años después de Montecristi. Quito: ILDIS-FES, 2015.

BARRERA, A. Estudio de casos sobre planificación del desarrollo en América Latina. Quito: Estrategia Territorial Nacional (ETN) Trabajo preparado para ILPES-CEPAL, 2014

BARRERA, A. Estado actual y perspectivas del proceso de descentralización a nivel intermedio. Quito: CONCOPE-PNUD, 2004. 
BARRERA, A. Un Estado descentralizado para el desarrollo y la democracia. Quito: ILDIS, 2006.

BARRERA, A. \& RAMÍREZ, F. Ecuador: un modelo para (des) armar. Descentralización, disparidades regionales y modo de Desarrollo. Quito: Abya Yala, 1999.

BARRERA, A. \& RAMÍREZ, F. El conflictivo proceso de reforma estatal en el Ecuador de los noventa. Quito: Centro de Investigaciones CIUDAD, 2001.

BARRERA, A., UNDA, M., CARRIÓN, D., LARREA, C. \& OJEDA, L. Participación y sociedad en el Ecuador. Participación, Elementos para una reforma democrática. Quito: Centro de Investigaciones CIUDAD. 1998.

BOISIER, S. Algunas reflexiones para aproximarse al concepto de ciudad. Colombia: Ánfora, 2006.

BOISIER, S. El difícil arte de hacer región. Las regiones como actores territoriales del nuevo orden internacional. Cusco: Centro Bartolomé de las Casas, 1995.

BOISIER, S. La gestión de las regiones en el nuevo orden internacional: cuasi Estados y cuasi empresas. Santiago: 1992.

BOISIER, S. Posmodernismo territorial y globalización: regiones pivótales y regiones virtuales. Económicas CUC, 1994, Vol. 22, Nº1, No. 102, p. 16-29.

BOISIER, S. Post-scriptum sobre el desarrollo regional: Modelo reales y modelos mentales. Santiago de Chile: Pontifica Universidad Católica de Chile, 1998.

BOISIER, S. ¿Y si el desarrollo fuese una emergencia sistémica? Caracas: CLAD, 2003.

BOISIER, S. Política regional en una era de globalización. ¿Hace sentido en América Latina? Santiago de Chile: ILPES, 1996.

BRENNER, N. \& THEODORE, N. Las ciudades y las geografías del neoliberalismo realmente existente. Barcelona: Icaria Espacios Críticos, 2017.

BUITELAAR, R., ECHEVERRI, P., SILVA, R. \& RIFFO, L. Estrategias y políticas nacionales para la cohesión territorial. Santiago de Chile: CEPAL, 2015.

BUSTOS, B. \& PRIETO, M. Nuevas aproximaciones teóricas a las regiones-commodity desde la ecología política. Chile: EURE, 2019, Vol. 45, №135, p. 153-176.

CARRIÓN, A., MONTALVO, M.J. \& LÓPEZ, M. Hacia la construcción de un espacio estatal: el territorio en la planificación del desarrollo en Ecuador, 2007-2017. En F. Enríquez (Ed.). Territorialización de la política pública y gobernanza. Quito: Abya Yala, 2019, p. 35-66. 
CÓDIGO ORGÁNICO DE ORGANIZACIÓN TERRITORIAL, AUTONOMÍAS Y DESCENTRALIZACIÓN. Quito: Registro Oficial Suplemento 303, 2010.

CORAGGIO, J., SABATE, A. \& COLMAN, O. La Cuestión Regional en América Latina. Quito: Ediciones: Centro de Investigaciones CIUDAD, 1989.

CUERVO, L. Globalización y Territorio. Santiago: Instituto Latinoamericano y del Caribe de Planificación Económica y Social (ILPES), 2006.

DE MATTOS, C. La obstinada marginalidad de las políticas territoriales: el caso latinoamericano. Globalización y metamorfosis metropolitana en América Latina. Revista de Geografía Norte Grande, 2010, N³8, p. 157-160.

DECRETO EJECUTIVO 878. Quito: Registro Oficial 268, 2008.

FERNÁNDEZ, V., VIGIL, J. \& SEVAL, M. Explorando la región. Territorios, escalas y relacionalidades. Revista de Geografía Norte Grande, 2012, N51, p. 21-41.

GIMÉNEZ, G. Apuntes para una teoría de la región y de la identidad regional. México D.F.: Estudios sobre las culturas contemporáneas, 1994.

GÓMEZ, S. Región y regionalización: su teoría y su método. El nuevo orden espacial del territorio argentino. Tiempo y Espacio, 2011, N²7, p. 83-112.

JUNAPLA. Plan de Desarrollo. Quito: s.n., 1965.

JUNAPLA. Plan de Desarrollo 1964-1973. Quito: s.n., 1963.

JUNAPLA. Plan Integral de Transformación y Desarrollo. Quito: s.n., 1975.

JUNAPLA. Regiones Económicas del Ecuador, su integración y desarrollo. 1965.

LIPIETZ, A. El capital y su espacio. México: Siglo XXI, 1983.

MAIGUASHCA. J. El proceso de integración nacional en el ecuador: el rol del poder central, 18301895. En E. Ayala Mora (Ed). Nueva Historia del Ecuador. Quito: CEN / FLACSO / CERLAC, 1994.

MANZANAL, M. \& ROFMAN, A. Las economías regionales de la Argentina. Buenos Aires: CEALCEAUR, 1989.

MASSIRIS, Á. Retos del Ordenamiento Territorial en Contexto de Descentralización y Autonomía en América Latina. Cuenca: 2014.

MILLER, D. Sobre la Nacionalidad, Autodeterminación y Pluralismo Cultural. Barcelona: Paidós, 1997. 
MUÑOZ, P., LARREA, A.M. \& GARCÍA, J.F. El nuevo pacto territorial: Descentralización y autonomías en la nueva Constitución. Quito: Documento inédito, 2008.

NORMA TÉCNICA DE DESCONCENTRACIÓN DEL EJECUTIVO. Quito: Registro Oficial, Acuerdo Ministerial 1, 2013.

QUINTERO, R. La cuestión regional y el poder. Quito: Corporación Editora Nacional, 1991.

REHREN, A., ORELLANA, A., ARENAS, F. \& HIDALGO, R. La regionalización en un contexto de urbanización regional: Desde los desafíos a las propuestas de nuevos criterios de zonificación para el caso chileno. Revista de Geografía Norte Grande, 2018, º69, p. 191-209.

ROFMAN, A. Desigualdades regionales y concentración económica: el caso argentino. Buenos Aires: Amorrortu, 1974.

ROFMAN, A. Notas teórico-empíricas sobre el proceso de desigualdades regionales en la Argentina. Buenos Aires: Boletín de Estudios Latinoamericanos y el Caribe, 1979.

ROFMAN, A Y ROMERO, L. 1997. Sistemas Socioeconómicos y estructura regional en la Argentina. Buenos Aires: Amorrortu, 1997.

ROFMAN, A. Teoría y práctica de la planificación regional en América Latina. En L. Coraggio (Ed.). La cuestión regional en América Latina. Quito: Centro de Investigaciones CIUDAD, 1989.

SAINT-GEOURS, Y. La Sierra Centro-Norte (1830-1925). Historia y región en el Ecuador. Quito: Corporación Editora Nacional, 1994.

SANTOS, M. \& SILVEIRA, M.L. O Brasil: Território e Sociedade no início do século XXI. Rio de Janeiro: Récord, 2001.

SANTOS, M. Território, globalizacao e fragmentacao. SPaulo: Hucitec, 1994.

SENPLADES. Análisis: funcionalidad y conformación de las zonas de planificación. Quito: Documento de Trabajo, 2013.

SENPLADES. Caracterización de Regiones propuestas. Quito: Documento de Trabajo, 2007.

SENPLADES. Desarrollo territorial y reforma democrática del Estado. Quito: Documento de trabajo, 2007.

SENPLADES. Espacio, territorio y reforma democrática del Estado. Quito: s.n., 2007. Documento de Trabajo.

SENPLADES. Metodología de análisis y caracterización de propuestas de regionalización. Quito: Documento de Trabajo, 2007. 
SENPLADES. Plan Nacional de Desarrollo 2007-2010. Quito: s.n., 2007.

SENPLADES. Plan Nacional del Buen Vivir 2009 2013. Quito: s.n., 2009.

SENPLADES. Plan Nacional del Buen Vivir 2013-2017. Quito: s.n., 2013.

SILVA, I. Desarrollo económico local y competitividad territorial en América Latina. Santiago: CEPAL, 2005. 
